\title{
Primary Demyelination Induced by Exposure to Tellurium Alters Schwann Cell Gene Expression: A Model for Intracellular Targeting of NGF Receptor
}

\author{
A. D. Toews, ${ }^{1,3}$ I. R. Griffiths, ${ }^{4}$ E. Kyriakides, ${ }^{4}$ J. F. Goodrum, ${ }^{2,3}$ C. E. Eckermann, ${ }^{3}$ P. Morell, ${ }^{1,3}$ and C. E. \\ Thomson ${ }^{4}$ \\ 'Department of Biochemistry and Biophysics, 2Department of Pathology, and ${ }^{3}$ Brain and Development Research Center, \\ University of North Carolina, Chapel Hill, North Carolina 27599 and ${ }^{4}$ Applied Neurobiology Group and Department of \\ Veterinary Surgery, University of Glasgow, Bearsden, Glasgow G61 1QH, Scotland
}

Exposure of developing rats to tellurium results in a highly synchronous segmental demyelination of peripheral nerves with sparing of axons; this demyelination is followed closely by a period of rapid remyelination. Demyelination occurs subsequent to a tellurium-induced block in the synthesis of cholesterol, the major myelin lipid. We utilized the techniques of Northern blotting, in situ hybridization, and immunocytochemistry to examine temporal alterations in Schwann cell gene expression related to demyelination and remyelination. Tellurium-induced demyelination is associated with downregulation of myelin protein expression and a corresponding upregulation of NGF receptor (NGF-R) and glial fibrillary acidic protein (GFAP) expression. Steady-state mRNA levels (expressed on a "per nerve" basis) for $P_{0}$, the major myelin protein, were decreased by about $50 \%$ after 5 d of tellurium exposure, while levels of mRNA for NGF-R and GFAP were markedly increased (about 15-fold). In situ hybridization of teased fibers suggested that the increase in steady-state mRNA levels for NGF-R was primarily associated with demyelinated internodes and not with adjacent unaffected internodes. Although $P_{0}$ message was almost totally absent from demyelinating internodes, it was also reduced in normal-appearing internodes as well. This suggests that limiting the supply of a required membrane component (cholesterol) may lead to partial downregulation of myelin gene expression in all myelinating Schwann cells.

In partially demyelinated internodes, NGF-R and GFAP immunofluorescence appeared largely confined to the demyelinated regions. This suggests specific targeting of these proteins to local areas of the Schwann cell where there is myelin loss. These results demonstrate that demyelination is associated with reversion of the affected Schwann cells to a precursor cell phenotype. Because axons remain intact, our results suggest that these changes in Schwann cell gene

\footnotetext{
Received Feb. 12, 1992; revised Apr. 10, 1992; accepted Apr. 17, 1992.

We are grateful to Drs. G. Lemke, N. J. Cowan, and E. M. Shooter for the various cDNA clones, and to Drs. E. M. Johnson and J.-M. Matthieu for the various antisera. We thank M. C. Land for technical assistance and A. May and N. D. Goines for photography. This study was supported by U.S. Public Health Service Grants ES-01104 and NS-11615 in a ccnter receiving core support from HD-03110, and by funds from the Wellcome Trust.

Correspondence and reprint requests should be addressed to Arrel D. Toews, Ph.D., 321 BSRC Building, CB\# 7250, University of North Carolina, Chapel Hill, NC 27599.

Copyright $@ 1992$ Society for Neuroscience $0270-6474 / 92 / 123676-12 \$ 05.00 / 0$
}

expression do not require input from a degenerating axon, but instead may depend on whether concerted synthesis of myelin is occurring.

In normal adult peripheral nerve, myelinating and nonmyelinating Schwann cells express different proteins. The myclin proteins, including $\mathrm{P}_{0}$, myelin basic protein (MBP), and myelinassociated glycoprotein, are expressed only in myelinating Schwann cells (Mirsky et al., 1980; Trapp and Quarles, 1982, 1984; Griffiths et al., 1989; Jessen et al., 1990). Nonmyelinating Schwann cell gene expression is very similar to that of the developmental "precursor cell" phenotype. Nonmyelinating Schwann cells express NGF receptor (NGF-R), glial fibrillary acidic protein (GFAP), and neural cell adhesion molecule (NCAM), among others. All of these proteins are significantly downregulated in myelinating Schwann cells (Jessen and Mirsky, 1984; Mirsky et al., 1986; Jessen et al., 1990), although expression of N-CAM and another cell-adhesion molecule, $\mathrm{Ll}$, continues at "nodal regions" of myelinating Schwann cells and on the nodal axon of the adult (Rieger et al., 1986).

Models frequently used for study of Schwann cell differentiation in the PNS involve transection or crush of nerves in adult animals. In vivo, a viable axon is necessary not only to initiate the commitment of Schwann cells to myelination, but also to maintain the differentiated Schwann cell. Transection of a peripheral nerve is followed by rapid and profound downregulation of the myelin protein genes (LeBlanc et al., 1987; Gupta et al., 1988, 1990; Trapp et al., 1988; LeBlanc and Poduslo, 1990; Thompson et al., 1991) and loss of galactocerebroside (Jessen et al., 1987b). There is a concomitant reexpression of NGF-R (Taniuchi et al., 1986, 1988; Heumann et al., 1987; Johnson et al., 1988; Bosch et al., 1989) and N-CAM (Nieke and Schachner, 1985; Daniloffet al., 1986; Jessen et al., 1987a) in the denervated Schwann cells. The processes involved in myelination during development are recapitulated during the regeneration that occurs subsequent to a nerve crush (Gupta et al., 1988, 1990; LeBlanc and Poduslo, 1990; Mitchell et al., 1990).

Certain toxicant-induced disordcrs produce segmental demyelination (e.g., lead neuropathy; Krigman et al., 1980). These models offer the potential for studying demyelination and remyelination without the added complexity of axonal changes. Exposure of developing rats to a diet containing tellurium results in a peripheral neuropathy characterized by a highly synchronous, transient primary demyelination without observable ef- 

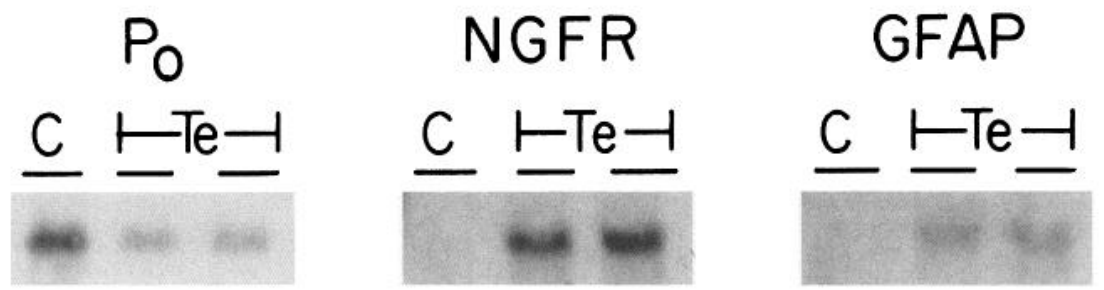

Figure 1. Northern blot analysis of steady-state mRNA levels for $\mathrm{P}_{0}$, NGF-R, and GFAP. Samples of total RNA from sciatic nerves of control (C) rats and from rats exposed to tellurium $(T e)$ for $5 \mathrm{~d}$ were separated on denaturing agarose gels, transferred to nylon membranes, and hybridized with cDNA probes specific for each protein. The same samples were used for all three hybridizations; data for NGF-R and GFAP are from the same blot $\left(5 \mu \mathrm{g} /\right.$ lane), while data for $\mathrm{P}_{0}$ are from a different blot containing $0.3 \mu \mathrm{g} /$ lane. The two Te lanes are from separate animals. Although the signals for NGF-R and GFAP were very weak in control sciatic nerve samples, longer exposures than those shown in this figure allowed quantitation of relative message levels in these samples. Because the Te lanes in the longer exposure times needed to quantitate control message levels may have been overexposed, the calculated degree of upregulation ( $\sim 15$-fold for both NGF-R and GFAP) may actually be an underestimate.

fects on the axon. Demyelination is followed closely by a period of rapid remyelination (Lampert and Garrett, 1971; Duckett et al., 1979; Said et al., 1981; Takahashi, 1981; Bouldin et al., 1988). Tellurium blocks cholesterol synthesis, specifically by inhibiting the squalene epoxidase reaction that converts squalene to lanosterol (Harry et al., 1989; Wagner-Recio et al., 1991). Although the tellurium-induced block is systemic, it is sciatic nerve myelin that is preferentially affected. This is presumably due to the structural requirement for cholesterol to stabilize the multilamellar myelin membranes. Although this requirement also holds for CNS myelin, the rate of myelin synthesis, and thus the demand for newly synthesized cholesterol, is much greater in sciatic nerve than in brain.

As in the regeneration models, there is a reversible downregulation of mRNA expression for the major structural proteins of myelin $\left(\mathrm{P}_{0}\right.$ and $\left.\mathrm{MBP}\right)$ during the demyelinating phase (Toews et al., 1990), and upregulation of mRNA expression for the NGF-R and the POU domain protein, SCIP (Toews et al., 1991a). We now extend our observations to correlation of the expression of specific markers with the presence or absence of pathological alterations in individual Schwann cells.

Preliminary findings have been presented (Griffiths et al., 1992; Toews et al., 1992).

\section{Materials and Methods}

Experimental model. Animals were exposed to tellurium as previously described (Harry et al., 1989). Briefly, 20-d-old male Long-Evans or Sprague-Dawley rats were placed on a diet containing either $1.1 \%$ or $1.5 \%$ tellurium for 7 consecutive days, after which a normal (Purina rodent chow) diet was provided ad libitum. Sciatic nerves were removed at times ranging from 1 to $30 \mathrm{~d}$ after initiation of tellurium exposure. The same nerves were used for RNA isolation and morphological studies (in situ hybridizations and immunocytochemistry); a $5 \mathrm{~mm}$ segment was immersion fixed in $4 \%$ paraformaldehyde, $0.1 \%$ glutaraldehyde, and the remainder was used for RNA isolation.

RNA isolation and Northern blot analyses. For total RNA preparation, nerves were homogenized in guanidine isothiocyanate and the RNA purified by centrifugation through cesium chloride with subsequent ethanol precipitation (Toews et al., 1990; based on Chirgwin et al., 1979). RNA species were separated according to molecular weight on denaturing $0.7 \%$ agarose gels containing formaldehyde (Pauley et al., 1984) and transferred to Zeta-Probe nylon blotting membranes (Bio-Rad Laboratories, Richmond, CA). Filters were hybridized with ${ }^{32} \mathrm{P}$-labeled cDNA probes (synthesized using the random-primer method; Feinberg and Vogelstein, 1983) specific for either $P_{0}$ (Lemke and Axel, 1985), NGFR (Raedeke et al., 1987), or GFAP (Lewis et al., 1984). Filters were washed and then exposed to x-ray film; at least three autoradiography films with varying exposure times were analyzed for each hybridization. Levels of RNA were determined by quantitative densitometry of the autoradiograms. To control for variability in sample handling, values so obtained were normalized to the amount of ribosomal RNA in each lane, as assayed with a ${ }^{32} \mathrm{P}$-end-labeled oligonucleotide (Maniatis et al., 1982) specific for $28 \mathrm{~S}$ ribosomal RNA.

Preparation of nerves for cytochemical studies. Fresh-frozen $10 \mu \mathrm{m}$ sections of sciatic nerve were cut, air dried, fixed in $4 \%$ paraformaldehyde for $5 \mathrm{~min}$, washed, and redried. Sections were stored at $-20^{\circ} \mathrm{C}$ until use (usually overnight, but no longer than 2 weeks). Fibers were loosely teased from small bundles of fixed or unfixed sciatic nerve on poly-L-lysine-coated slides, allowed to air dry, and then processed as described previously (Griffiths et al., 1989). Each slide contained both tellurium-treated and control nerves for parallel processing and evaluation.

In situ hybridization. Antisense and sense RNA probes labeled with ${ }^{35} \mathrm{~S}$-UTP were transcribed. Full details of the $\mathrm{P}_{0}$ probe have been published previously (Griffiths et al., 1989; Mitchell et al., 1990). The probe for the rat NGF-R was a 1.7 kilobase EcoRI/BglII fragment of the pNGFR.1 plasmid (Raedeke et al., 1987), subcloned into pBluescript II KS ( \pm ; Stratagene). Hybridizations were performed on frozen sections and on bundles of teased fibers essentially as described previously (Griffiths et al., 1989; Mitchell et al., 1990). Autoradiograms of teased fibers were stained with Sudan black B to visualize myelin. Frozen sections were lightly counterstained with hematoxylin to visualize nuclei.

Immunocytochemistry. Antiserum to rat NGF-R (clone 192), obtained from Boehringer-Mannheim and Dr. E. M. Johnson (Taniuchi et al., 1986, 1988), was used at a concentration of $1.25 \mu \mathrm{g} / \mathrm{ml}$. Antiserum to GFAP (Dako) was used at 1:750. MBP antiserum, from Dr. J.-M. Matthieu (Centre Hospitalier Universitaire Vaudois, Lausanne, Switzerland), was used at 1:500. Secondary antisera for immunofluorescence were FITC-conjugated goat anti-mouse IgG1 (Southern Biotechnology) used at 1:100; FITC-conjugated goat anti-rabbit IgG (Sigma) used at 1:130; TRITC-conjugated goat anti-rabbit IgG (Sigma) used at 1:200, and FITC-conjugated goat anti-mouse IgG (Sigma) used at 1:75. Mouse peroxidase-antiperoxidase (ICN) and goat anti-mouse IgG (Sigma) were used for immunoperoxidase staining.

Primary and secondary antibodies were diluted in PBS plus $1 \%$ normal goat serum. NGF-R antibody was applied to unfixed nerves for 60 min at room temperature. Additionally, NGF-R antibody was used on fibers fixed for $30 \mathrm{~min}$ at $4^{\circ} \mathrm{C}$ in $3 \%$ paraformaldehyde. Following incubation with secondary antibody for $30 \mathrm{~min}$ at room temperature, fibers were fixed for $10 \mathrm{~min}$ in $3 \%$ paraformaldehyde. Unfixed nerves for GFAP staining were extracted with $0.1 \%$ Triton X-100 for 10 min at room temperature and then fixed for $20 \mathrm{~min}$ at room temperature in paraformaldehyde, and then antiserum was applied overnight at $4^{\circ} \mathrm{C}$. Some fibers were labeled for NGF-R as above, fixed in 3\% paraformaldehyde, extracted in $0.1 \%$ Triton $\mathrm{X}-100,0.1 \%$ deoxycholate for 30 min at room temperature, and then stained overnight at $4^{\circ} \mathrm{C}$ with antiMBP. Slides were mounted in $0.1 \%$ paraphenylenediamine in PBS/ glycerol. In some cases, fibers were processed by the standard peroxidase-antiperoxidase technique (Van Noorden and Polak, 1983) and then counterstained with Sudan black B, after immunostaining for NGF-R as described above. In some instances, fibers were stained with propidium iodide to demonstrate nuclei prior to mounting (Jones and Kniss, 1987).

\section{Results}

The sequence of events following exposure of developing rats to a tellurium-containing diet begins with a primary segmental 


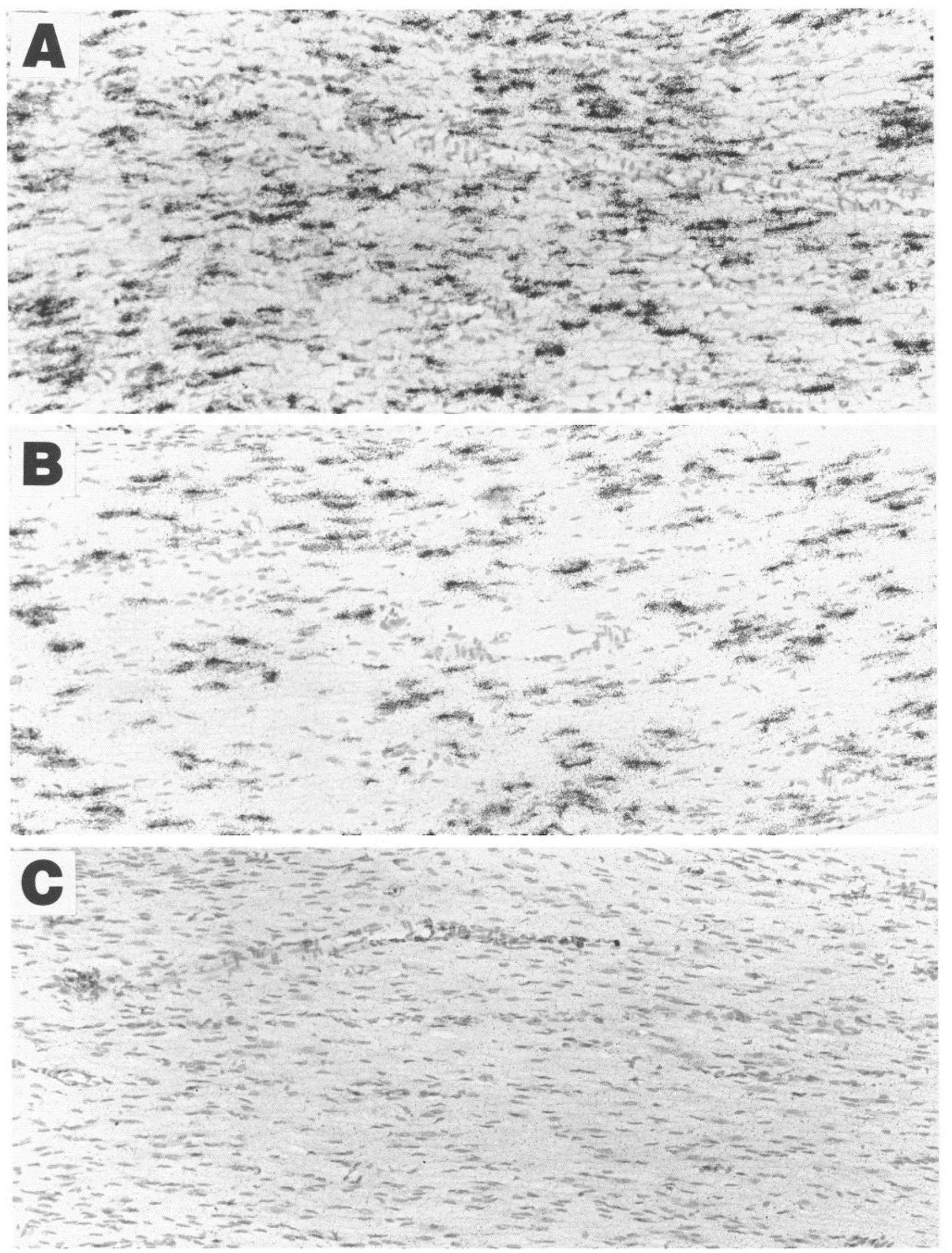

Figure 2. In situ hybridization of frozen sections from sciatic nerves of control and tellurium-treated rats, using riboprobes for $\mathrm{P}_{0}$ protein. Sections were prepared as described in Materials and Methods. $A$, Control sciatic nerve hybridized with antisense $\mathrm{P}_{0}$ riboprobe. Schwann cells are heavily labeled. $B$, Sciatic nerve from animal exposed to tellurium for $5 \mathrm{~d}$, hybridized with antisense $\mathrm{P}_{0}$ riboprobe. There are fewer labeled cells, and the cells are labeled less intensely than in control nerve. $C$, Control nerve hybridized with sense $\mathrm{P}_{0}$ riboprobe. Only background grains are present. Sections have been lightly counterstained with hematoxylin to visualize nuclei. Magnification, $145 \times$. 
demyclination and dedifferentiation of Schwann cells, and progresses through Schwann cell proliferation and subsequent remyelination of demyelinated internodes. Morphological examinations carried out during this investigation confirmed those reported previously in that axons remained intact and did not show any morphological evidence of damage.

Steady-state $m R N A$ levels for $P_{0}$ are reduced by about $50 \%$, while those for NGF-R and GFAP are greatly increased. When expressed on a "per nerve" basis, message levels for $\mathrm{P}_{0}$ were decreased by about $50 \%$ after $5 \mathrm{~d}$ of tellurium exposure (Fig. 1; see also Toews et al., 1990, 1991a). There was a corresponding upregulation ( $\sim 15$-fold) of mRNA expression for NGF-R and GFAP (Fig. 1), coincident with the downregulation for $\mathrm{P}_{0}$.

$m R N A$ for $P_{0}$ is significantly reduced even in many Schwann cells maintaining intact internodes. In situ hybridizations of frozen sections from sciatic nerves from rats treated with tellurium for $5 \mathrm{~d}$ suggest that the decrease in steady-state mRNA levels for $P_{0}$ detected by Northern blot analysis results from fewer positive cells, as well as from a generalized decrease in signal intensity in positive cells (Fig. 2).

Distribution of $m R N A$ for $P_{0}$ and $N G F-R$ in teased fibers. Localization of mRNA for $P_{0}$ and NGF-R was also examined by in situ hybridization techniques in teased fiber preparations of sciatic nerve, using antisense RNA probes. In control nerves, $\mathrm{P}_{0}$ mRNA showed a strong focal perinuclear signal located in the mid-internode (Fig. $3 A$, inset), as previously reported (Griffiths et al., 1989; Mitchell et al., 1990). Signal intensity is related to fiber size (larger internodes are more intensely labeled) and is of approximately equal intensity in contiguous internodes along the same fiber (Griffiths et al., 1991).

Teased fiber preparations were examined 3, 5, 7, and $9 \mathrm{~d}$ after beginning tellurium exposure. No obvious morphological abnormalities were detected at the light microscopic level at $3 \mathrm{~d}$ but were present at later times. Demyelination occurred randomly along fihers, with the myelin sheath of many internodes remaining intact as judged by Sudan black B staining. The animals used in this portion of the study were fed a lower level of tellurium than those above (1.1\% vs $1.5 \%)$ so that the few demyelinated internodes could be readily contrasted with adjacent unaffected internodes. Along with the longer exposure times to increase sensitivity for identifying message in the demyelinated internodes, these procedures obscured the generalized decrease in message apparent in the less-exposed frozen sections described above.

The presence of localized zones of demyelination at the paranodes during the early stages of demyelination is compatible with considerable expression of $\mathrm{P}_{0}$ mRNA (Fig. 3A). More extensive loss of myelin along all or most of an internode is, however, invariably associated with a drastic decrease in $\mathrm{P}_{0}$ signal (Fig. $3 B$, oblique arrow 2). Intact internodes adjacent to the demyelinating segments continue to express $P_{0}$ mRNA. The remyelination that closely follows the tellurium-induced demyelination is associated with proliferation of Schwann cells and the formation of short internodes (Said et al., 1981). By 5 $\mathrm{d}$, and more obviously by $9 \mathrm{~d}$, a demyelinated internode is often associated with several $\mathrm{P}_{0}$-expressing Schwann cells, with the message level increasing in these cells over this time period (Fig. 3C).

NGF-R mRNA expression was studied in teased fibers at 5 and $9 \mathrm{~d}$ after beginning exposure to tellurium (Fig. 4). Signal was absent or very low in intact internodes (Fig. $4 A$ ). A typical partially demyelinated internode is shown in Figure $4 B$. Some partially demyelinated internodes had variable expression of NGF-R, with some showing upregulation and others no increase. However, it is evident that in the majority of cases, even small amounts of myelin loss in an internode are associated with increased NGF-R mRNA expression, which is localized in the perinuclear area. Segmental demyelination (involving the entire internode) is also associated with NGF-R upregulation. Most newly formed intercalated Schwann cells involved in remyelination are also positive (Fig. $4 C-E$ ).

Immunocytochemical localization of myelin proteins, $N G F$ $R$, and $G F A P$ along internodes. Teased fibers of sciatic nerves from rats exposed to tellurium for 6 and $7 \mathrm{~d}$ were immuno-

\footnotetext{
Figure 3. In situ hybridization of teased fibers from sciatic nerves of control and tellurium-treated rats, using an antisense RNA probe for $\mathrm{P}_{0}$ protein. After development of the audioradiogram, the slide was stained with Sudan black B to demonstrate myelin. In all panels, nodes are indicated by vertical solid arrows and affected internodes lie within open arrows. $A, A$ single internode in the early stages of demyelination. There is patchy loss of myelin, especially in the paranodal regions, and focal swellings of the sheath. The intensity of the $\mathbf{P}_{0}$ signal, which is located in the mid-internodal perinuclear area, appears similar to a normal fiber from an age-matched control rat (inset) at this stage of demyelination. The animal was exposed to tellurium for $5 \mathrm{~d}$. $B$, A single continuous fiber is shown in sequential longitudinal photographic strips, arranged vertically. The fiber begins at the top left and continues, in a left to right orientation, to the bottom right corner. A normal intact internode with strong $\mathrm{P}_{0}$ expression in the perinuclear region (oblique arrow l) can be compared to the adjacent demyelinated internode, where $\mathbf{P}_{0}$ intensity in the perinuclear region (oblique arrow 2) is virtually absent. The animal was exposed to tellurium for $7 \mathrm{~d}$. $C$, A single continuous fiber, depicted as described for $B$, from the sciatic nerve of a rat $9 \mathrm{~d}$ after beginning a $7 \mathrm{~d}$ exposure to tellurium. The original internode contained within the open arrows has been demyelinated; Schwann cell proliferation has occurred with the formation of at least six intercalated segments that are associated with strong $P_{0}$ expression. This constitutes the early stages of remyelination. Unaffected internodes, also with strong $\mathrm{P}_{0}$ expression, are present on both sides of this remyelinating internode. Magnification: $A, 300 \times ; B$ and $C, 550 \times$.

Figure 4. Teased fibers from sciatic nerves of control and tellurium-treated animals hybridized with antisense RNA probe for NGF-R and counterstained with Sudan black B to demonstrate myelin. In all panels, nodes are indicated by the larger vertical arrows and affected internodes are shown by open arrows. A, Myelinated fiber from a control rat. No NGF-R signal is detectable. The perinuclear area is indicated by a small arrow. $B$, Single continuous fiber, beginning at the top left and continuing in serial longitudinal photographic strips to the bottom right, from the sciatic nerve of a rat exposed to tellurium for $5 \mathrm{~d}$. There are small areas of paranodal myelin loss at each node and a slight swelling of the fiber, due to myelin vacuolation, just to the left of the nuclear area in the lower strip. Silver grains, denoting NGF-R mRNA, are present in the perinuclear area (small arrow). $C$, Single continuous fiber from sciatic nerve of a rat exposed to tellurium for $5 \mathrm{~d}$, showing a single demyelinated internode. The demyelinated area contains several foci of silver grains (some indicated by small arrows), one of which, in the center, is larger. When stained with propidium iodide, these foci correspond to nuclei and probably represent upregulation of NGF-R in postmitotic Schwann cells. $D$, Another single continuous fiber, showing a demyelinated internode, with the small arrows indicating some of the NGF-R-expressing cells in the demyelinated area. All of these foci are associated with nuclei when stained with propidium iodide and probably represent new Schwann cells. $E$, Part of a demyelinated internode showing foci of silver grains (small arrows). Parts of the original sheath are still visible as darkly stained areas. Magnification: $A, 390 \times ; B, 320 \times ; C$ and $D, 250 \times ; E, 400 \times$.
} 

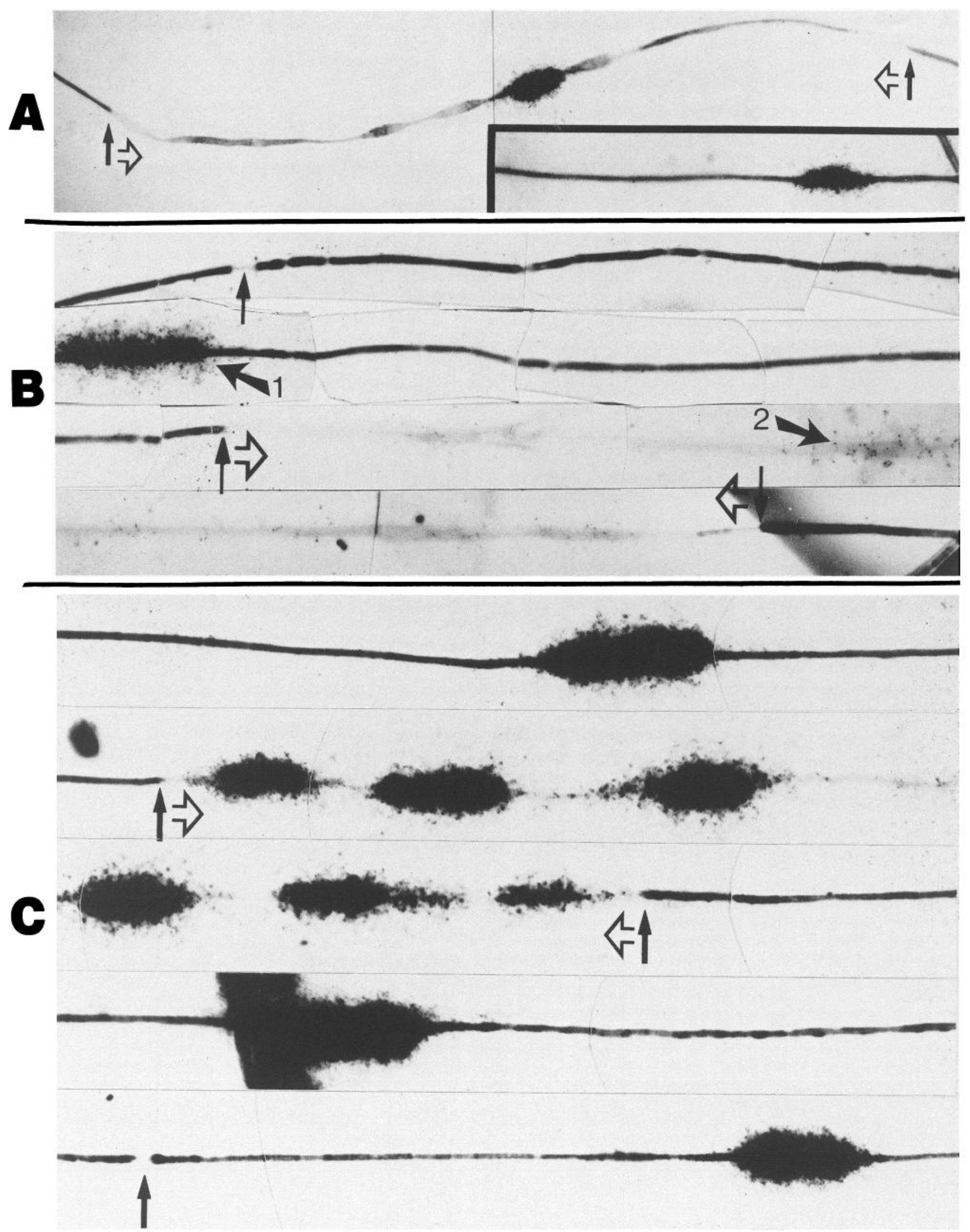


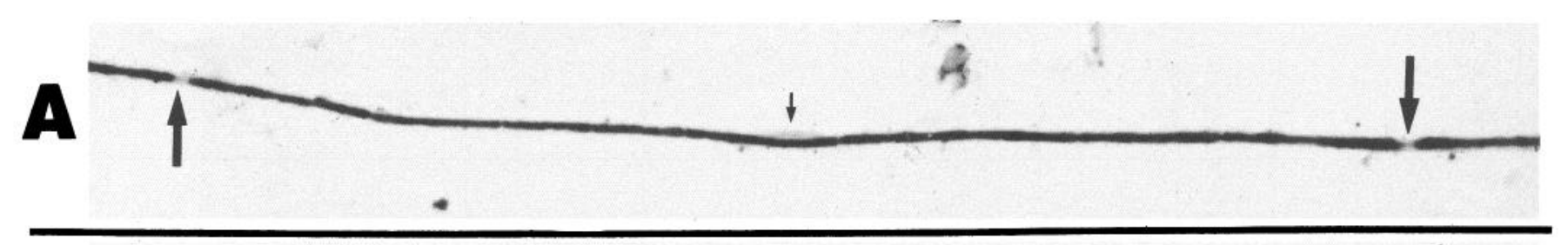

B
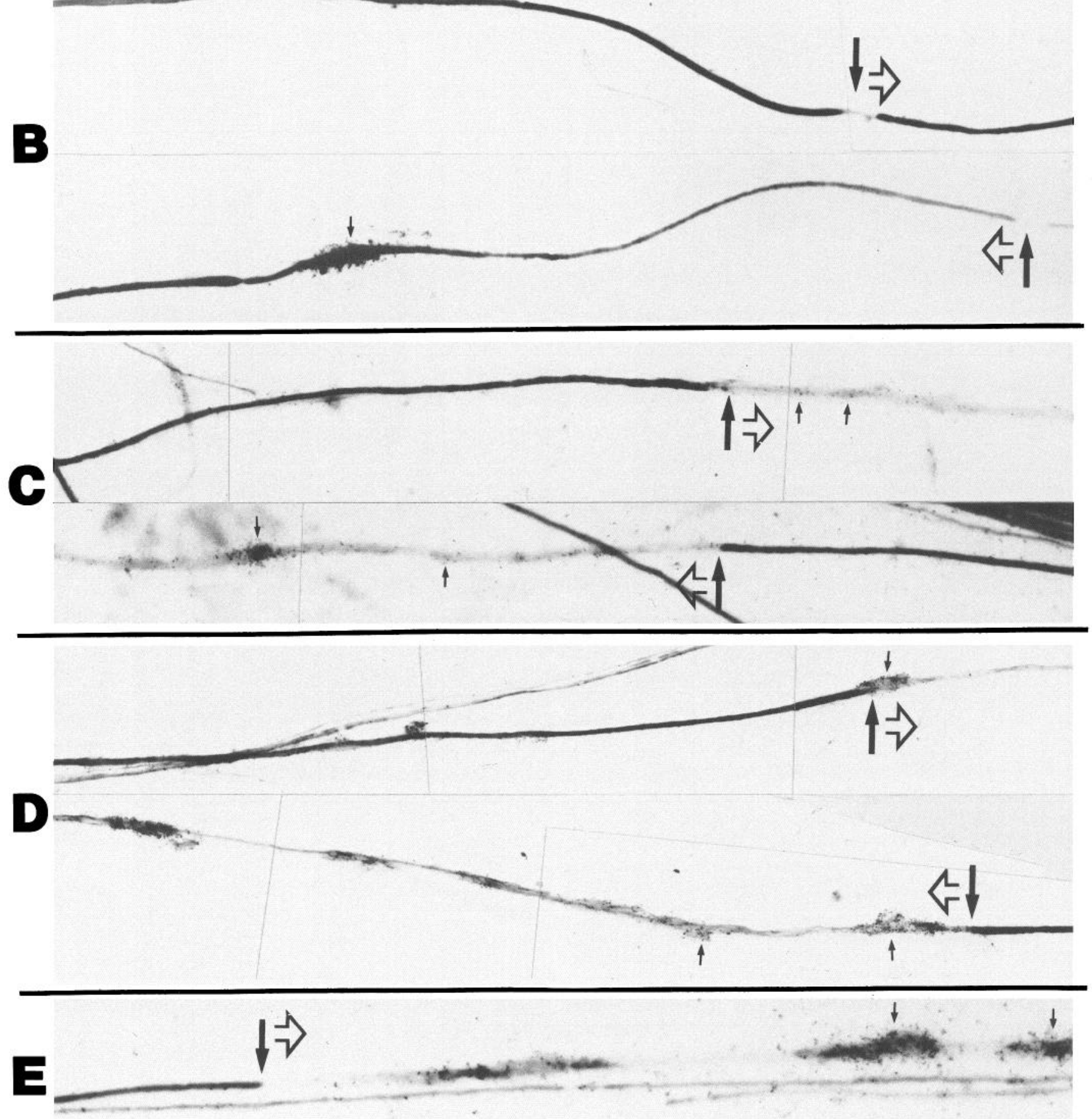

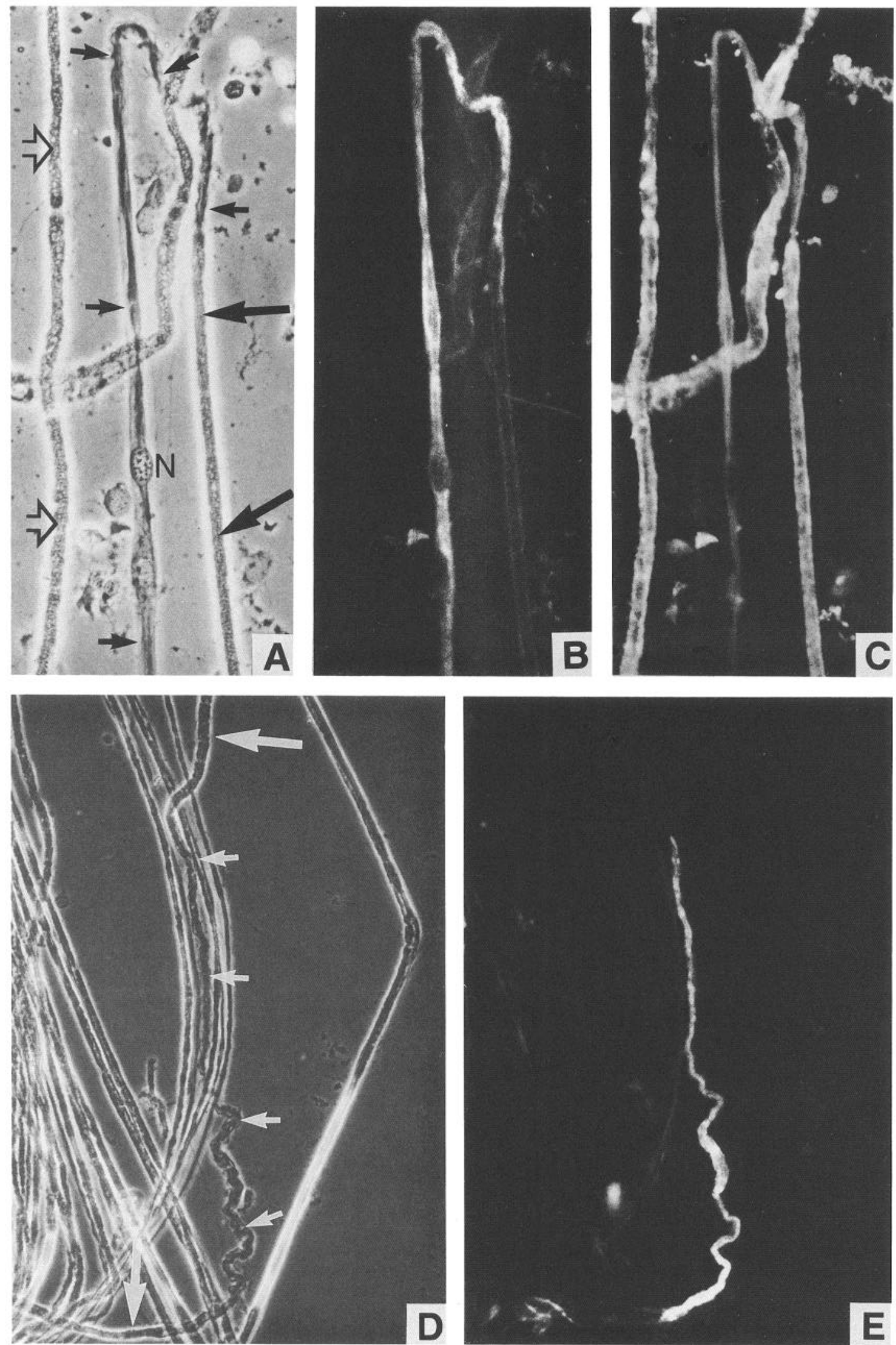

Figure 5. Teased fiber preparation from a rat exposed to tellurium for $7 \mathrm{~d}$. The same fibers are shown in phase contrast $(A)$, immunostained for NGF-R and visualized with fluorescein optics $(B)$, and immunostained for MBP and visualized with rhodamine optics $(C)$. A normal myelinated fiber (open arrows) stains for MBP but not NGF-R. A second myelinated fiber, from left center to top, also stains intensely for MBP, but not for NGF-R. Another fiber, part of which is undergoing demyelination (small arrows), shows reactivity for NGF-R and reduced myelin (MBP) staining. This fiber continues to an intact internode (large arrows) in which MBP staining is strong but NGF-R reactivity is absent. A nucleus, possibly from a Schwann cell, is indicated $(N)$ in the demyelinated area. Other fibers from the same animal are shown in phase contrast $(D)$ and immunostained for NGF-R $(E)$. The majority of fibers are normal and fail to stain for NGF-R. A single fiber shows an area of demyelination (small arrows) positive for NGF-R, and normal morphology (large arrows) on either side with no NGF-R staining. Magnification: $A-C, 360 \times ; D$ and $E, 170 \times$. 

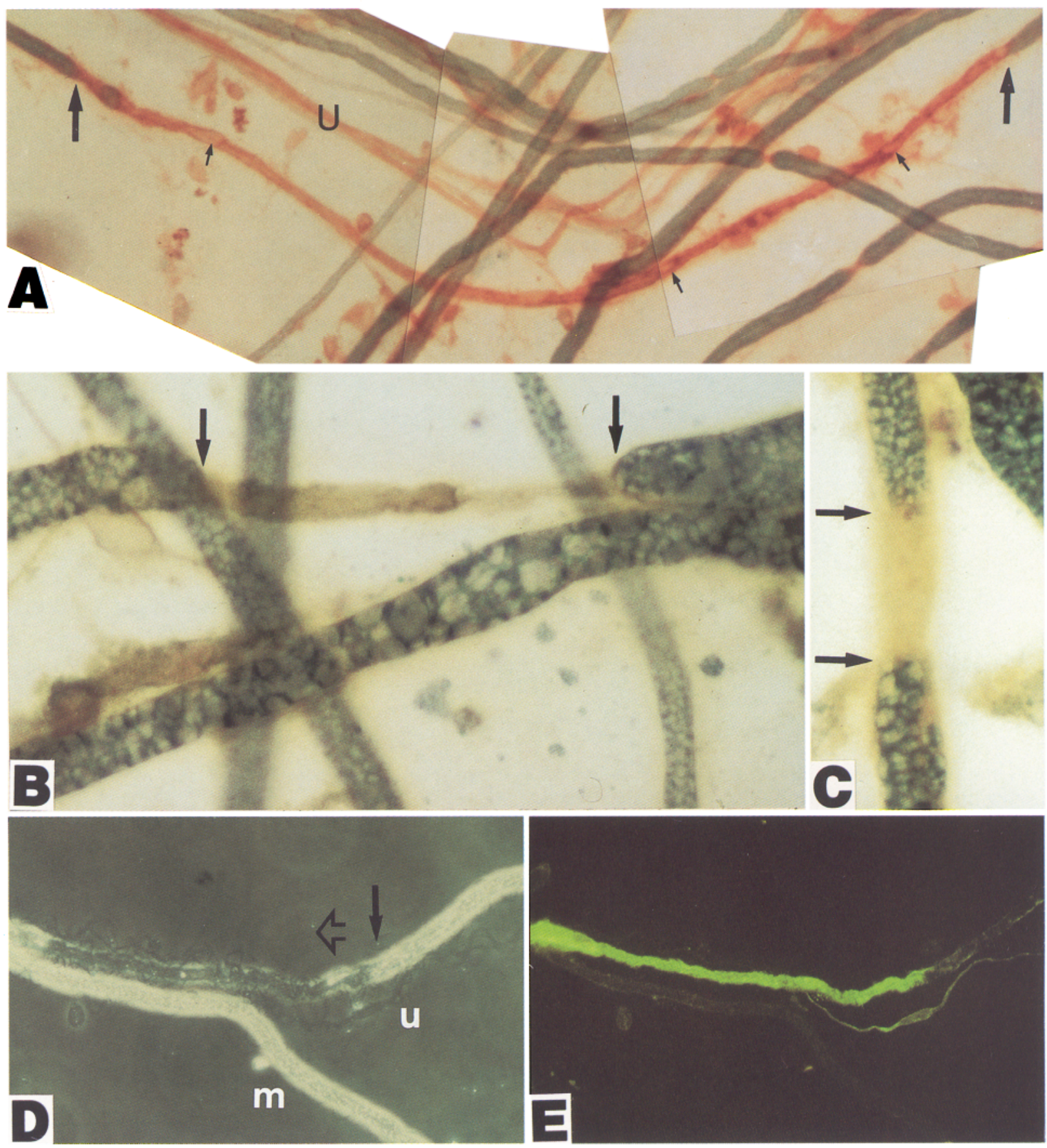

Figure 6. Teased fibers from the sciatic nerve of a rat exposed to tellurium for $7 \mathrm{~d}$. $A$, The preparation has been immunostained for NGF-R (brown) using the peroxidase-antiperoxidase technique. Normal myelin is stained greenish blue by Sudan black B. Schwann cells on a demyelinated internode (between vertical arrows) are strongly positive for NGF-R. Several nuclear outlines (small arrows) can be seen along its length. Unmyelinated fibers $(U)$ are also positive for NGF-R, a normal feature. $B$ and $C$, Fibers from the same rat immunostained for NGF-R and then counterstained with Sudan black B. Both panels show partial demyelination of an internode (between arrows) with a corresponding expression of NGF-R in the demyelinated areas. Nuclei are not associated with these areas, indicating that they are derived from the original internode and are not newly forming intercalated internodes. $D$ and $E$, Teased fibers from sciatic nerve of a rat exposed to tellurium for $7 \mathrm{~d}$ are shown in phase contrast $(D)$ and by immunofluorescence for NGF-R $(E)$. Two myelinated fibers and an unmyelinated fiber are present. One myelinated fiber $(m)$ is normal under phase optics $(D)$ and is unstained for NGF-R $(E)$. The other is partially demyelinated from the level marked by the solid arrow in the direction of the open arrow, and this area stains intensely for NGF-R. An unmyelinated fiber $(u)$ is also positive for NGF-R, a normal feature. Magnification: $A, 270 \times ; B$ and $C, 800 \times ; D$ and $E, 460 \times$.

stained for myelin proteins, NGF-R, and GFAP. Obvious demyelination is present at these times. Immunostaining with NGF-R antibody is seen in affected internodes, but not in adjacent intact internodes (Figs. $5 A-C, 6 A$ ). The staining profile of the unmyelinated fibers remains unaltered (positive for NGF$\mathrm{R}$, but negative for myelin proteins).

Demyelination often involves only part of an internode, and adjacent internodes are commonly intact. In partially demye- 

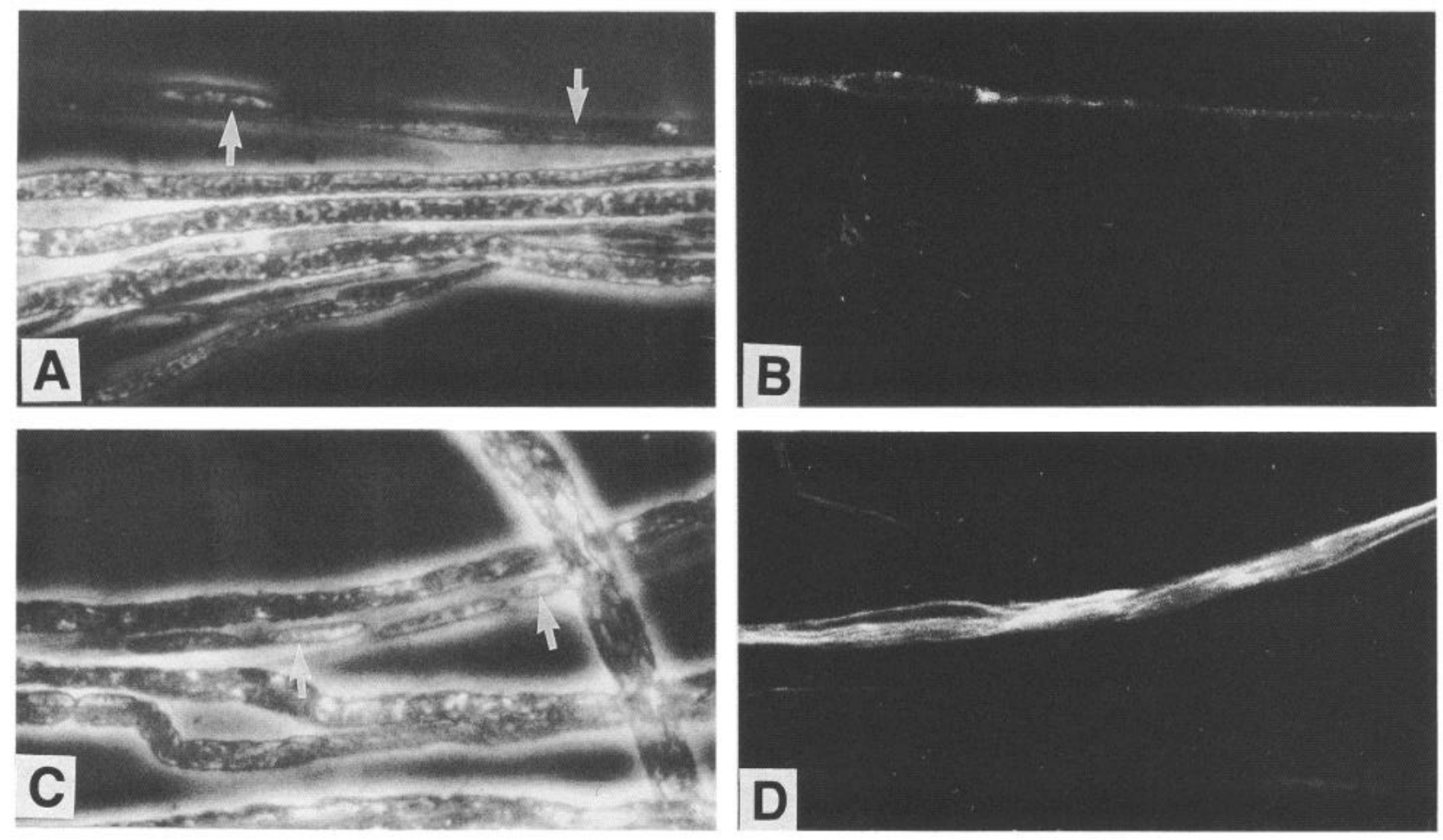

Figure 7. Teased fibers from a control rat sciatic nerve are shown in phase contrast in $A$ and $C$. These same fibers are shown under fluorescein optics after immunostaining for NGF-R $(B)$ and GFAP $(D)$, respectively. None of the myelinated fibers are stained for either antigen, while unmyelinated fibers (arrows) covered by nonmyelinating Schwann cells are positive for each antigen. Magnification, $670 \times$.

linated internodes, the NGF-R expression is most frequently colocalized with the zone(s) of demyelination, although some overlap with the still-myelinated part of the internode is not uncommon (Figs. 5, 6B-E). The antigen is present in the Schwann cells surrounding the axons. Combining the NGF-R immunostaining with propidium iodide fluorescence allowed nuclei to be visualized. Segmentally demyelinated internodes are associated with increased numbers of nuclei derived from Schwann cells and perhaps macrophages. In some fibers, however, short lengths of partial demyelination within an internode are associated with upregulation of NGF-R. This upregulation was not associated with any extra nuclei (Fig. $6 B, C$ ), indicating that such an area is not a newly formed intercalated segment but still part of the original internode. This finding suggests that a Schwann cell associated with a partially demyelinated internode can simultaneously exhibit molecules characteristic of both a myelinating and nonmyelinating phenotype.

Data from teased fibers of sciatic nerve from control animals confirm the findings of previous workers. Briefly, myelinated internodes are positively stained with antibody to a structural myelin protein (data not shown; MBP was the myelin protein selected for immunocytochemistry because it is very immunogenic and can be well resolved). In contrast, these internodes are negative for staining with antibodies for NGF-R and GFAP (Fig. 7). Each sample of teased fibers usually also contains several small bundles of unmyelinated fibers; the Schwann cells associated with these fibers stain intensely for NGF-R and GFAP.

Immunostaining for GFAP in teased fibers from telluriumtreated rats is also increased in a pattern similar to that seen for NGF-R (Fig. 8). GFAP expression is associated with demyelinated internodes, while adjacent internodes do not stain. Again, expression of this protein seems localized to areas of demyelination.

\section{Discussion}

Tellurium-induced demyelination is associated with a reversion of affected Schwann cells to a nonmyelinating or precursor phenotype. Thus, myelin protein genes are downregulated while NGF-R and GFAP are upregulated (see also Toews et al., 1990, 1991a). These events occur in parallel with a synchronous segmental demyelination. In situ hybridization for $\mathrm{P}_{0}$ mRNA on frozen sections suggests that, in addition to the almost complete downregulation of expression of message in demyelinated internodes, there is also a generalized decrease in $\mathrm{P}_{0}$ expression in all myelinating Schwann cells. Because of the nature of the tellurium-induced metabolic insult - a block in synthesis of cholesterol necessary for myelin synthesis and maintenance-the entire program of myelin gene expression may be somewhat downregulated in all myelin-producing cells. This would contribute to the total observed decreases in steady-state mRNA levels for myelin proteins, as detected by Northern blot analysis. More detailed studies to elucidate the quantitative aspects of the relationship between the degree of inhibition of cholesterol synthesis, the amount of decrease in $\mathrm{P}_{0}$ message levels, and the degree of demyelination seem warranted. Such information could cast light on how synthesis of myelin proteins and myelin lipids is coordinated. Because exposure to tellurium alters cholesterol synthesis in all tissues, it is possible that certain aspects of steroid hormone homeostasis are disturbed. Steroid hormones are known to regulate gene expression at the transcriptional level (Evans and Arriza, 1989), and translational regulation of myelin protein synthesis by steroids has also been reported (Verdi and Cam- 

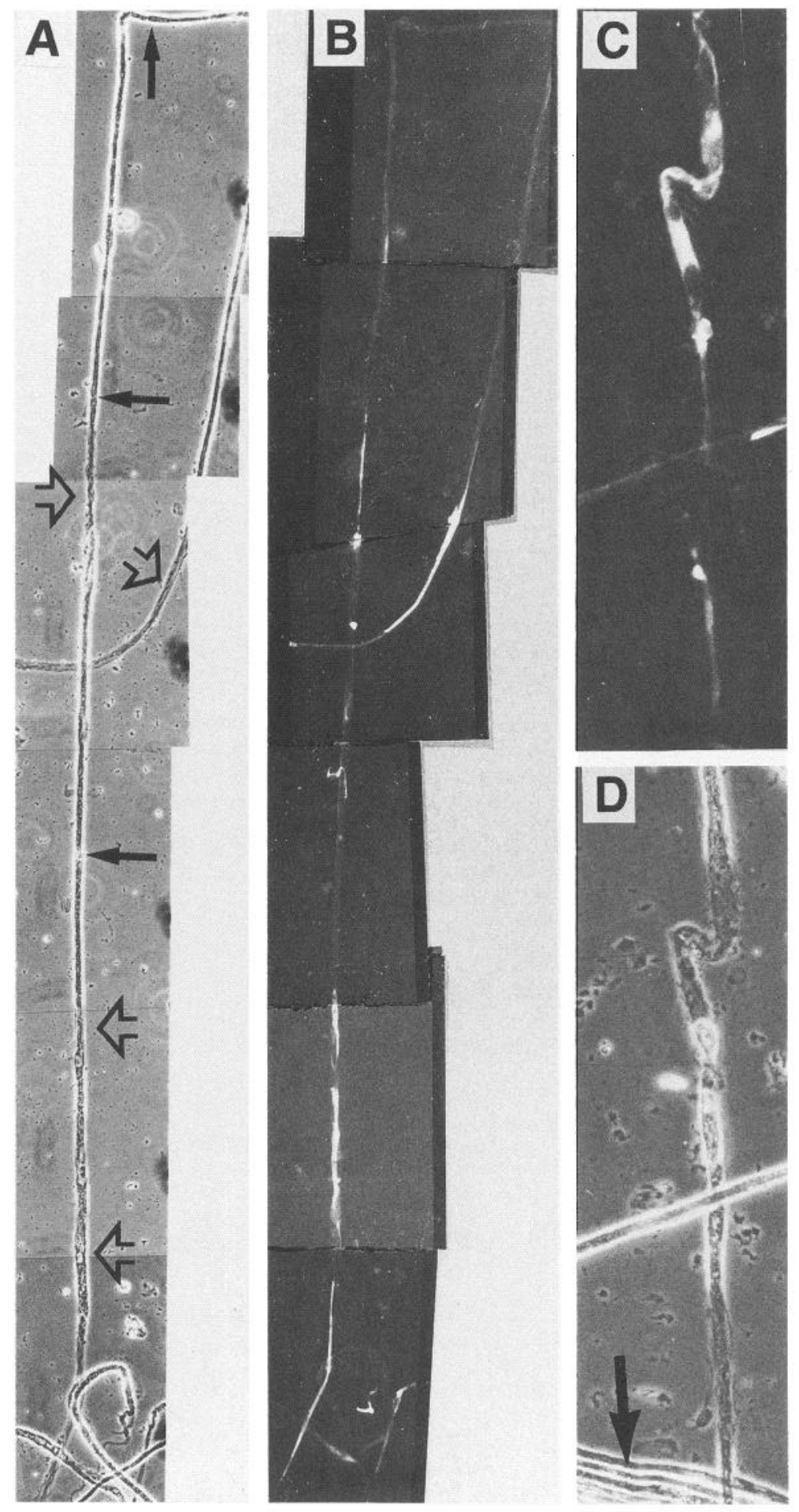

Figure 8. $A$ and $B$, Teased fiber preparation from the sciatic nerve of a rat exposed to tellurium for $7 \mathrm{~d}$, shown in phase contrast $(A)$ and by immunofluorescence for GFAP $(B)$. Nodes are indicated by solid arrows and demyelinated areas by open arrows. The fiber continues out of field at the top right and then curves down back into the field. This area to the top right is normal. GFAP expression is associated with the demyelinated internodes. $C$, and $D$, Teased fibers from the same animal showing a demyelinated fiber in phase contrast $(D)$ running vertically and expressing GFAP $(C)$. A small bundle of normal fibers (arrow in $D$ ) are unstained for GFAP $(C)$. The "bubbled" punctate staining pattern for GFAP immunofluorescence is probably due to the presence of myelin debris within the Schwann cells. Magnification: $A$ and $B$, $120 \times$; $C$ and $D, 200 \times$. pagnoni, 1990). We note that the effects of tellurium intoxication are tissue specific in some respects. Cholesterol synthesis is upregulated in liver, but not in sciatic nerve, in response to the tellurium-induced metabolic block; this upregulation in liver is reflected in increased levels of mRNA and enzyme activity for 3-hydroxy-3-methylglutaryl-CoA reductase, the rate-limiting enzyme in cholesterol biosynthesis (Toews et al., 1991b).

The model of tellurium-induced demyelination is informative of certain aspects of the control of maintenance of the myelin sheath. From the many published axotomy experiments (for review, see Schwartz, 1987; Fawcett and Keynes, 1990), it is clear that maintenance of the Schwann cell myelinated phenotype requires axonal contact. In the case of tellurium-induced demyelination, however, morphological criteria suggest that the demyelination and dedifferentiation of Schwann cells are not associated with defects of the axon or axolemma. Furthermore, the rapidity of remyelination also suggests that any necessary axonal myelinating signal remains available to the Schwann cell throughout this period. Thus, it appears that changes in the Schwann cell phenotype indicative of dedifferentiation can be 
associated with demyelination, even in the presence of continued contact with or signal(s) from the axon.

The capacity of a cell to express the genes involved in myelination is, in part, dependent on the continuing ability of the cell to synthesize and maintain myelin membrane. Thus, a lack of cholesterol could itself be directly responsible for the shutdown in myelin protein expression. Alternatively, breakdown products of myelin could stimulate dedifferentiation. We consider unlikely a third possibility that the signal to upregulate NGF-R and GFAP cxpression and downregulate myelin protein expression results from the limited loss of axonal contact corresponding to partial demyelination of an internode, although we acknowledge lack of experimental proof of this view.

Cell division per se is not the signal for alterations in gene expression in this model. In cultured Schwann cells, there is an inverse relationship between expression of myelination genes and cell division; dividing cells are $P_{0}$ negative but NGF-R and GFAP positive. The converse occurs when the cell withdraws from division and begins to myelinate (Morgan et al., 1991). In tellurium-induced demyelination, demyelinated internodes are eventually associated with Schwann cell proliferation and remyelination. However, we detected small zones of paranodal demyelination with upregulation of NGF-R and GFAP, but no associated Schwann cell proliferation, suggesting that cell division per se is not likely to be responsible for these alterations. Indecd, downrcgulation of the $\mathrm{P}_{0}$ genc associated with Wallerian degeneration is not prevented by inhibition of Schwann cell mitosis (C. E. Thomson and I. R. Griffiths, unpublished observations).

Loss of small amounts of myelin in a given internode results in dedifferentiation of the affected Schwann cell; proteins newly expressed in this state appear targeted to the demyelinated areas. The extent of demyelination following tellurium exposure varied from segmental (involving the whole internode) to focal, usually paranodal, demyelination. Changes in $\mathrm{P}_{0}$ gene expression at the mRNA level were much more profound in internodes showing myelin loss, while upregulation of NGF-R mRNA expression was virtually confined to demyelinated internodes. In most instances, paranodal demyelination was associated with similar alterations of gene expression, although examples were found of small areas of myelin loss unaccompanied by any obvious change of molecular phenotype. These internodes may have been in the early stages of demyelination. The majority of internodes with a small zone(s) of demyelination exhibited NGF$\mathrm{R}$ mRNA expression. In partially demyelinated internodes, reexpression of NGF-R and GFAP proteins was largely localized in areas of focal demyelination rather than the still-myelinated regions. These findings suggest that a relatively small loss of myelin (in relation to the total myelin volume of the internode) can result in reversion to a precursor cell phenotype, and that the proteins produced are largely targeted to the demyelinated areas of the Schwann cell. This again tends to indicate a considerable local control over genes associated with the process of myelination. During normal development, myelinating Schwann cells transiently express both myelin proteins, which are being upregulated, and NGF-R and GFAP, which are being downregulated (Jessen et al., 1990). It is not yet known if there is a similar selective distribution of thesc molccules in the newly myelinating internodes of sciatic nerve during development.

Our studies indicate that signals from a degenerating axon are not required for the Schwann cell dedifferentiation and proliferation that occur subsequent to demyelination. These process- es, along with the subsequent redifferentiation of Schwann cells to a myelinating phenotype, may occur independently of any axonal perturbations. This experimental model may prove useful for examining gene expression of Schwann cells in situ, without the complications of axonal degeneration and regeneration.

\section{References}

Bosch EP, Zhong W, Lim $\mathrm{K}$ (1989) Axonal signals regulate expression of glia-maturation factor beta in Schwann cells: an immunohistochemical study of injured sciatic nerves and cultured Schwann cells. J Neurosci 9:3690-3698.

Bouldin TW, Samsa G, Earnhardt T, Krigman MR (1988) Schwanncell vulnerability to demyelination is associated with internodal length in tellurium neuropathy. J Neuropathol Exp Neurol 47:41-47.

Chirgwin JM, Przybyla AE, MacDonald RJ, Rutter WJ (1979) Isolation of biologically active ribonucleic acid from sources enriched in ribonuclease. Biochemistry 18:5294-5299.

Daniloff JK, Levi G, Grument M, Rieger F, Edelman GM (1986) Altered expression of neuronal cell adhesion molecules induced by nerve injury and repair. J Cell Biol 103:929-945.

Duckett S, Said G, Streletz LG, White RG, Galle P (1979) Telluriuminduced neuropathy: correlative physiological, morphological and electron microprobe studies. Neuropathol Appl Neurobiol 5:265278

Evans RM, Arriza JL (1989) A molecular framework for the actions of glucocorticoid hormones in the nervous system. Neuron 2:11051112.

Fawcett JW, Keynes RJ (1990) Peripheral nerve regeneration. Annu Rev Neurosci 13:43-60.

Feinberg AP, Vogelstein B (1983) A technique for radiolabelling DNA restriction endonuclease fragments to high specific activity. Anal Biochem 132:6-13.

Griffiths IR, Mitchell LS, McPhilemy K, Morrison S, Kyriakides E, Barrie JA (1989) Expression of myelin protein genes in Schwann cells. J Neurocytol 18:345-352.

Griffiths IR, McCulloch MC, Barrie JA, Kyriakides E (1991) Expression of $P_{0}$ mRNA in myelinating Schwann cells is related to fibre size. J Neurocytol 20:396-403.

Griffiths IR, Toews AD, Kyriakides E, Thomson CE (1992) Expression of axonally regulated Schwann cell genes in tellurium-induced demyelination. Neuropathol Appl Neurobiol 18:299.

Gupta SK, Poduslo JF, Mezei C (1988) Temporal changes in $P_{0}$ and MBP gene expression after crush-injury of the adult peripheral nerve. Mol Brain Res 4:133-141.

Gupta SK, Poduslo JF, Dunn R, Roder J, Mezei C (1990) Myelinassociated glycoprotein gene expression in the presence and absence of Schwann cell-axonal contact. Dev Neurosci 12:22-33.

Harry GJ, Goodrum JF, Bouldin TW, Wagner-Recio MW, Toews AD, Morell P (1989) Tellurium-induced neuropathy: metabolic alterations associated with demyelination and remyelination in rat sciatic nerve. J Neurochem 52:938-945.

Heumann R, Lindholm D, Bandtlow C, Meyer M, Radeke MJ, Misko TP, Shooter E, Thoenen H (1987) Differential regulation of mRNA encoding nerve growth factor and its receptor in rat sciatic nerve during development, degeneration and regeneration: role of macrophages. Proc Natl Acad Sci USA 84:8735-8739.

Jessen KR, Mirsky R (1984) Non-myelin-forming Schwann cells coexpress surface proteins and intermediate filaments not found in myelinforming cells: a study of Ran-2, A5E3 antigen and glial fibrillary acidic protein. J Neurocytol 13:923-934.

Jessen KR, Mirsky R, Morgan L (1987a) Myelinated, but not unmyelinated axons, reversible down-regulate N-CAM in Schwann cells. J Neurocytol 16:681-688.

Jessen KR, Mirsky R, Morgan L (1987b) Axonal signals regulate the differentiation of non-myelin-forming Schwann cells: an immunohistochemical study of galactocerebroside in transected and regenerating nerves. J Neurosci 7:3362-3369.

Jessen KR, Morgan L, Stewart HJS, Mirsky R (1990) Three markers of adult non-myelin-forming Schwann cells, (Ran-1), A5E3 and GFAP: development and regulation by neuron-Schwann cell interactions. Development 109:91-103.

Juhnson EM, Taniuchi M, DiStefano PS (1988) Expression and possible function of nerve growth factor receptors on Schwann cells. Trends Neurosci 11:299-304. 
Jones KH, DA Kniss (1987) Propidium iodide as a nuclear counterstain for immunofluorescence studies on cells in culture. J Histochem Cytochem 35:123-125.

Krigman MK, Bouldin IW, Mushak P (1980) Lead. In: Experimental and clinical neurotoxicology (Spencer PS, Schaumburg HH, eds), pp 490-507. Baltimore: Williams and Wilkins.

Lampert PW, Garrett RS (1971) Mechanism of demyelination in tellurium neuropathy. Electron microscopic observations. Lab Invest $25: 380-388$

LeBlanc AC, Poduslo JF (1990) Axonal modulation of myelin gene expression in the peripheral nerve. J Neurosci Res 26:317-326.

LeBlanc $A C$, Poduslo JF, Mezei C (1987) Gene expression in the presence or absence of myelin assembly. Mol Brain Res 2:57-67.

Lemke G, Axel R (1985) Isolation and sequence of a cDNA encoding the major structural protein of peripheral myelin. Cell 40:501-508.

Lewis SA, Balcarek JM, Krek V, Shelanski M, Cowan NJ (1984) Sequence of a cDNA clone encoding mouse glial fibrillary acidic protein: structural conservation of intermediate filaments. Proc Natl Acad Sci USA 81:2743-2746.

Maniatis T, Fritsch EF, Sambrook J (1982) Molecular cloning, pp 122-123. Cold Spring Harbor, NY: Cold Spring Harbor Laboratory.

Mirsky R, Winter J, Abney ER, Pruss RM, Gavrilovic J, Raff MC (1980) Myelin-specific proteins and glycolipids in rat Schwann cells and oligodendrocytes in culture. J Cell Biol 84:483-494.

Mirsky R, Jessen KR, Schachner M, Goridis C (1986) Distribution of the adhesion molecules N-CAM and Ll on peripheral neurons and glia in adult rats. $J$ Neurocytol 15:799-815.

Mitchell LS, Griffiths IR, Morrison S, Barrie JA, Kirkham D, McPhilemy K (1990) Expression of myelin protein gene transcripts by Schwann cells of regenerating nerve. J Neurosci Res 27:125-135.

Morgan L, Jessen KR, Mirsky R (1991) The effects of cAMP on differentiation of cultured Schwann cells: progression from an early phenotype $(\mathrm{O} 4+)$ to a myelin phenotype $\left(\mathrm{P}_{0}+\right.$, GFAP-, N-CAM-, NGF-receptor-) depends on growth inhibition. J Cell Biol 112:457467.

Nieke J, Schachner M (1985) Expression of the neural cell adhesion molecules Ll and N-CAM and their common carbohydrate cpitope L2/HNK-1 during development and after transection of the mouse sciatic nerve. Differentiation 30:141-151.

Pauley RJ, Parks WP, Popko BJ (1984) Expression and demethylation of germinally-transmitted $\mathrm{BALB} / \mathrm{c}$ mouse mammary tumor virus DNA in Abelson MuLV B-lymphoid cell lines. Virus Res 1:381-400.

Raedeke MJ, Misko TP, Hsu C, Herzenberg LA, Shooter EM (1987) Gene transfer and molecular cloning of the rat nerve growth factor receptor. Nature 325:593-597.

Rieger F, Daniloff JK, Pincon-Raymond M, Crossin KL, Grumet M, Edelman GM (1986) Neuronal cell adhesion molecules and cytotactin are colocalized at the node of Ranvier. J Cell Biol 103:379391.

Said G, Duckett S, Sauron B (1981) Proliferation of Schwann cells in tcllurium-induced demyelination in young rats. A radioautographic and teased nerve fiber study. Acta Neuropathol (Berl) 53:173-179.
Schwartz M (1987) Molecular and cellular aspects of nerve regencration. CRC Crit Rev Biochem 22:89-110.

Taniuchi M, Clark HB, Johnson EM (1986) Induction of nerve growth factor receptor in Schwann cells after axotomy. Proc Natl Acad Sci USA 83:4094-4098.

Taniuichi M, Clark HB, Schweitzer JB, Johnson EM (1988) Expression of nerve growth factor receptors by Schwann cells of axotomized peripheral nerves: ultrastructural location, suppression by axonal contact and binding properties. J Neurosci 8:664-681.

Takahashi $T$ (1981) Experimental study on segmental demyelination in tellurium neuropathy. Hokkaido J Med Sci 56:105-131.

Thompson CE, Mitchell LS, Griffiths IR, Morrison S (1991) Retarded Wallerian degeneration following peripheral nerve transection in C57BL/6/Ola mice is associated with delayed down-regulation of the $P_{0}$ gene. Brain Res 538:157-160.

Toews AD, Lee SY, Popko B, Morell P (1990) Tellurium-induced neuropathy: a model for reversible reductions in myelin protein gene expression. J Neurosci Res 26:501-507.

Toews AD, Eckermann CE, Lee SY, Morell P (1991a) Primary demyelination induced by exposure to tellurium alters mRNA levels for nerve growth factor receptor, $2^{\prime}, 3^{\prime}$-cyclic nucleotide $3^{\prime}$-phosphodiesterase, myelin proteolipid protein, and SCIP in rat sciatic nerve. Mol Brain Res 11:321-325.

Toews AD, Goodrum JF, Lee SY, Eckermann E, Morell P (1991b) Tellurium-induced alterations in 3-hydroxy-3-methylglutaryl-CoA reductase gene cxpression and enzyme activity: differential effects in sciatic nerve and liver suggest tissue-specific regulation of cholesterol synthesis. J Neurochem 57:1902-1906.

Toews AD, Griffiths IR, Kyriakides E, Thomson CE, Eckermann CE, Morell P (1992) Schwann cell gene expression during primary demyelination. Trans Am Soc Neurochem 23:156.

Trapp BD, Quarles RH (1982) Presence of myelin-associated glycoprotein correlates with alterations in the periodicity of peripheral myelin. J Cell Biol 92:877-882.

Trapp BD, Quarles RH (1984) Immunocytochemical localization of the myelin-associated glycoprotein. Fact or artifact? J Neuroimmunol $6: 231-249$

Trapp BD, Hauer P, Lemke G (1988) Axonal regulation of myelin protein mRNA levels in actively myelinating Schwann cells. J Neurosci 8:3515-3521.

Van Noorden S, Polak JM (1983) Immunocytochemistry today. Techniques and practice. In: Immunocytochemistry. Practical applications in pathology and biology (Polak JM, Van Noorden S, eds), pp 1142. Bristol: Wright PSG.

Verdi JM, Campagnoni AT (1990) Translational regulation by steroids: identification of a steroid modulatory element in the 5 -untranslated region of the myelin basic protein messenger RNA. I Biol Chem 265:20314-20320.

Wagner-Recio M, Toews AD, Morell P (1991) Tellurium blocks cholesterol synthesis by inhibiting squalene metabolism: preferential vulnerability to this metabolic block leads to peripheral nervous system demyelination. J Neurochem 57:1891-1901. 